\title{
Evaluation of an implemented Mini-CEX program for workplace- based assessment at Rehman Medical College, Peshawar, Khyber Pakhtunkhwa.
}

1. MBBS, MHPE, M.Phil PG Diploma Health Studies In-Charge of Medical Education, Rehman Medical College, Peshawar.

2. MBBS (Pak), MD (US),

Ph.D (Genetics) Director Research

Rehman Medical College, Peshawar. 3. MBBS

In-Charge Clinical Skills Center Rehman Medical College, Peshawar.

4. B-Ed, M-Ed, M.Phil (Education)

Senior Instructor Medical Education

Rehman Medical College, Peshawar.

Correspondence Address:

Dr. Mahrukh Ikram Shah

Department of Medical Education

Rehman Medical College, Peshawar.

mahrukh.shah@rmi.edu.pk

Article received on:

29/09/2020

Accepted for publication:

$11 / 01 / 2021$

\begin{abstract}
Mahrukh Ikram Shah ${ }^{1}$, Iftikhar Qayum ${ }^{2}$, Nazish Bilal ${ }^{3}$, Sajid Ahmed ${ }^{4}$
\end{abstract}
\begin{abstract}
Objective: To evaluate the feasibility and acceptability of Mini-CEX as a formative WPBA tool at Rehman Medical College. To compare the annual exam short case scores of students with their internal Mini-CEX scores. Study design: Cross Sectional study. Setting: Rehman Medical College, Peshawar. Period: January to February 2016. Material \& Methods: Mini-CEX was implemented for the first time in a medical college of Khyber Pakhtunkhwa after training of faculty \& students on simulators. 100 MBBS students of Final Professional were included in the study through universal sampling. Completed Mini-CEX forms were collected weekly by Department of Medical Education (DME), and data entered in an Excel file. Mini-CEX scores of graduates were reviewed, compared and correlated with Khyber Medical University (KMU) practical exam scores in the same subjects for short cases. Results: 84 students were selected after data cleaning. Total required Mini-CEX were, 2338, submitted were 2563 with maximum mean submission/student of 5.32 in Obs/Gyn against a required mean of $3.32(n=83$, total rotation period $=04$ weeks). The minimum requirement was 01 Mini-CEX/week. Total mean submission for all clinical disciplines was 7.67/student against a required mean of 6.27/ student, showing ease and feasibility in implementation and student compliance. Significant correlation with KMU annual examination scores was observed only for Surgery $(p=0.04)$. The correlation was insignificant for the other 03 disciplines of Medicine, Pediatrics and obstetrics and Gynecology with $p>0.05$. Conclusion: Mini-CEX implementation is feasible and acceptable tool for formative WPBA in undergraduate clinical training. The student performance in MiniCEX does not have a major effect on their annual exams scores.
\end{abstract}

Key words: $\quad$ Formative Assessment, Implementation, Mini-CEX, Undergraduate Training.

Article Citation: Shah MI, Qayum I, Bilal N, Ahmed S. Evaluation of an implemented Mini-CEX program for workplace-based assessment at Rehman Medical College, Peshawar, Khyber Pakhtunkhwa. Professional Med J 2021; 28(9):1346-1350. https://doi.org/10.29309/TPMJ/2021.28.09.6120

\section{INTRODUCTION}

Assessment has a pivotal role in education and is a key driver of learning experiences. There have been a number of reforms in assessment in medical education over the course of time and multiple methods have been used to promote learning. ${ }^{1}$ The pursuit of a mode of formative assessment that would not only promote learning but help identify strengths and weaknesses of students and ensure feedback from facilitators was made in workplace-based assessment to enhance clinical competency. ${ }^{1-3}$ Mini-CEX is an assessment tool that in particular fulfills the need for having a broad range of content for clinical skill assessment, with an inbuilt feedback mechanism and could help improve professional behaviors of trainees/students..$^{2,4-7}$ Moreover, Mini-CEX is a valid and reliable structured formative assessment tool that lasts 15-20 minutes and enables an examiner to directly observe and assess a student while he/ she performs skills according to set criteria. ${ }^{1,2,8-10}$ With recent trends towards an outcome-based medical education, it is imperative to have means of formative workplace-based assessment that continually ensures student learning and development for patient safety. ${ }^{4,11,12}$

Literature reviewed regarded Mini-CEX as a valuable means for identifying learning gaps, observation of learning needs by faculty, and inculcating motivation for engagement in appropriate activities. ${ }^{2,13-15}$

In most clinical assessments such as OSCE, direct 
observation and feedback on skills is missing even in postgraduate training ${ }^{16}$ a shortcoming that is addressed by Mini-CEX. It assesses the student at the highest "does" level of Miller's pyramid that is not possible with tests of memory reproduction. ${ }^{13,16}$ It formatively helps the students in a continuous process of learning. ${ }^{5}$

The present study was done to evaluate the feasibility and acceptability, in implementation of Mini-CEX at Rehman Medical College (RMC), Peshawar, and its two affiliated teaching hospitals. It also compared the scores of students obtained in Mini-CEX during their undergraduate clinical rotations and annual KMU clinical exams scores. The standardized format of Mini-CEX was implemented after review by experts and training of students and assessors. It was the first medical college in Khyber Pakhtunkhwa to implement Mini-CEX as workplace-based assessment for its final professional MBBS students in 2015.

\section{MATERIAL \& METHODS}

Rehman Medical College implemented MiniCEX as an innovative assessment methodology. Different formative and summative assessment strategies were employed periodically within the academic sessions. However most of these were for testing of cognition and not skill. OSPE and OSCE were the major formative and summative work place-based assessment strategies used.

Mini-CEX was implemented when the first batch of RMC students reached final professional MBBS in 2015. It was deployed as workplace-based assessment tool for learning during their hospital rotations. The international standardized format used for Mini-CEX ${ }^{17}$ was evaluated and modified by expert clinician faculty for certain criteria for Pakistani context and implemented. Students and faculty were trained by conducting supervised mock sessions in Clinical Skills Center of RMC, and in hospital wards with simulators.

The students were required to submit a minimum of one (and a maximum of two) Mini-CEX per week per rotation to Department of Medical Education (DME). Three drop boxes were arranged in the two hospitals and in the Department of Medical Education into which the students could drop their filled Mini-CEX forms. The forms were collected at the end of each week by personnel from DME. The collected forms were compiled, data entered in Excel sheets for each student, and updated on a weekly basis. Forms which were incomplete or not signed by senior faculty were excluded from data.

To assess Mini-CEX performance the following criteria were used (adopted from the international standard format):

1. Medical interviewing skills

2. Physical Examination skill system

3. Professionalism / Humanistic qualities

4. Judgment / Topic assessment

5. Patient counseling skills

6. Organization efficiency

7. Overall clinical competence

8. Observed Procedure skills

Average scores for each student were calculated and entered for each mentioned criterion. Each criterion has three scoring levels as given in Table-I below:

\begin{tabular}{|c|c|c|}
\hline Below Satisfactory & Satisfactory & Superior \\
\hline $1-3$ & $4-6$ & $7-9$ \\
\hline
\end{tabular}

Table-I. Scoring levels for the assessment criteria given in Mini-CEX.

The students were given marks based on their obtained scores in the submitted Mini-CEX for any given criterion mentioned above. The individual scores were then summed up to calculate the total marks of each student and added to their internal assessment as per affiliated university. Ethical approval as obtained from the college research ethical committee.

\section{RESULTS}

Of 100 medical students, 16 were excluded after data cleaning (non-adherence to standard Mini-CEX form guidelines; incomplete forms; unsigned forms, etc.). The compliance of 84 Final Professional MBBS students with Mini-CEX was monitored throughout their final year hospital clerkships (Table-II). The details show over 100\% Mini-CEX submissions for Obs/Gyn and Pediatrics, 95\% for General Surgery, and 97\% for Medicine \& Allied Specialties. 


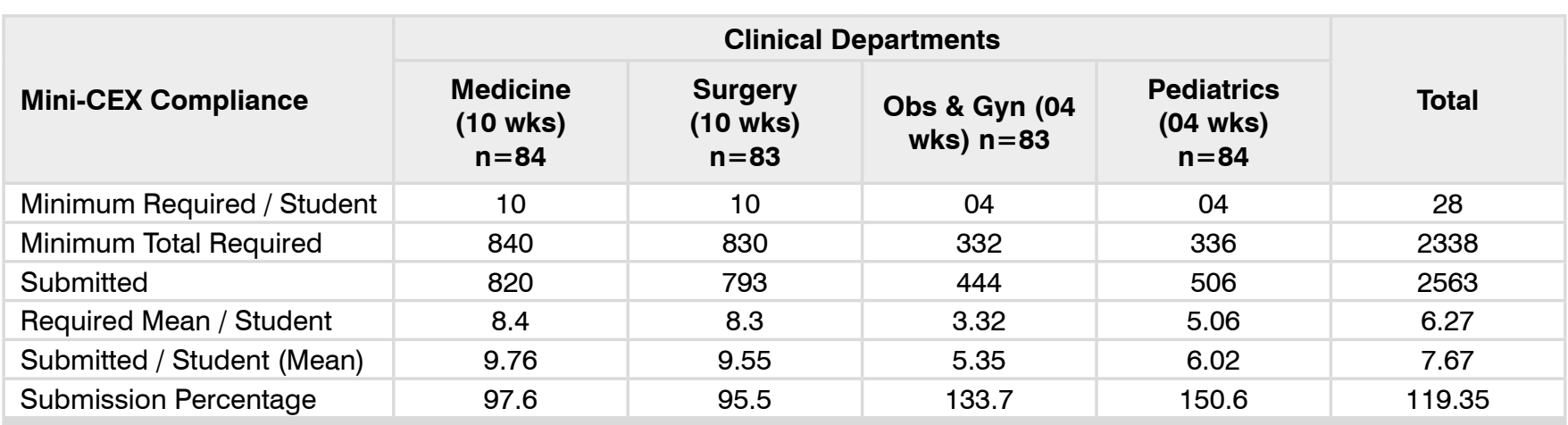

Table-II. Compliance of students with Mini-CEX requirements during their clinical rotations.

When the departmental undergraduate Mini-CEX scores were compared with the Khyber Medical University (KMU) annual exam scores significant correlation was observed only for Surgery scores, as shown in Table-III.

\begin{tabular}{|c|c|c|c|}
\hline $\mathrm{X}$-axis & Y-axis & $\mathbf{R}$ & $\begin{array}{c}\text { P-value } \\
\text { of } R\end{array}$ \\
\hline Medicine \& Allied & \multirow{5}{*}{$\begin{array}{c}\text { KMU } \\
\text { Annual } \\
\text { Result } \\
\text { Score }\end{array}$} & 0.016 & 0.885 \\
\hline General Surgery & & 0.226 & 0.040 \\
\hline Obs \& Gyne & & 0.112 & 0.316 \\
\hline Pediatrics & & -0.045 & 0.689 \\
\hline Overall Mini-CEX score & & 0.168 & 0.130 \\
\hline
\end{tabular}

Table-III. Correlation of departmental Mini-CEX scores with KMU annual clinical exam scores.

\section{DISCUSSION}

Studies have found Mini-CEX to be valid and reliable ${ }^{18,19}$, and can be incorporated in undergraduate clinical training as formative assessment; a study does identify the limitation in reliability due to examiner stringency, but the same study regards Mini-CEX as having good utility for undergraduate implementation. ${ }^{9}$

The present study indicates that Mini-CEX if properly implemented and monitored at undergraduate level can act as good means of WPB formative assessment. Enrolled students showed 95\%-150\% compliance regarding submission of required Mini-CEX. Although feasibility was regarded as poor by another study $(15 \%)^{13}$, the current study found it to be very feasible as indicated by the average submission rate of $75.5 \%$. Feasibility and acceptability of MiniCEX was also observed in literature reviewed. ${ }^{14,22}$
Students undertook Mini-CEX more than the minimum requirements set for them by DME in departments of Obs/Gyn and Pediatrics; this may reflect the greater need and motivation for clinical procedures and patient contact needed in these specialties. The less than $100 \%$ submission in Medicine and Surgery could be attributed to the fact that some assessors were junior facilitators, and not Trainee Medical Officers (or above rank), which was kept as a minimum requirement for expert feedback.

Correlations of Mini-CEX scores and the students' final professional MBBS examination scores of long and short cases were not obtained, or were too small and insignificant, except for General Surgery, where the correlation was weak but significant; this by itself may not have any value in terms of Mini-CEX improving General Surgery skills in preference to other disciplines. A recent study ${ }^{20}$, where correlations of Mini-CEX scores were done for multiple clinical disciplines also showed similar results, with no or weak correlations across the tested disciplines; reasons for such outcomes have been postulated as multiple undefined hidden elements, rater variability, professional level of rater, and the fact that Mini-CEX is a tool for assessing a single global dimension of clinical competency. ${ }^{21}$ Stronger and significant correlations have been reported when the Mini-CEX scores from a single discipline were correlated to summative assessment OSCE scores. ${ }^{20}$ In the present study the lack of corelation between the chosen scores could be due to the traditional unstructured pattern of clinical practical exams by the university. 
Validity and reliability of the tool has been documented by many in literature but studies identify further need for research to establish the validity and reliability of Mini-CEX due to various confounders like assessor variability, complexity of case, and patient gender., ${ }^{9,22}$ Since this study did not take into account the validity and reliability testing of Mini-CEX, further research shall be required to establish validity and reliability.

\section{CONCLUSION}

Mini-CEX is a feasible tool for formative workplace-based assessment with acceptability by undergraduate medical students and faculty in Pakistani context, with ease of implementation. However, to use Mini-CEX internal scores as a predictor for annual summative university clinical exam scores the later exams need to be structured and standardized especially the short case examinations. More research is needed to determine the validity and reliability of Mini-CEX.

Copyright $@ 11$ Jan, 2021.

\section{REFERENCES}

1. Lau Yanting $S$, Sinnathamby A, Wang DB, Tan Mong Heng M, Leong Wen Hao J, Lee SS, et al. Conceptualizing workplace based assessment in Singapore: Undergraduate mini-clinical evaluation exercise experiences of students and teachers. Tzu Chi Med J. [Internet]. 2016; 28(3):113-20.

2. Norcini $\mathrm{J}$, Burch V. Workplace-based assessment as an educational tool: AMEE Guide No. 31. Med Teach. [Internet]. 2007; 29(9):855-71.

3. Hoseini BL, Jafarnejad F, Mazloum SR, Foroughipour M. Practical experience of the mini-cex in undergraduate trainees. Procedia - Soc Behav Sci. [Internet]. 2013; 83:803-7.

4. Kogan JR, Holmboe ES, Hauer KE. Tools for direct observation and assessment of clinical skills of medical trainees: A systematic review. JAMA. 2009 Sep 23; 302(12):1316-26. doi: 10.1001/jama.2009.1365.

5. Weston PSJ, Smith CA. The use of mini-CEX in UK foundation training six years following its introduction: Lessons still to be learned and the benefit of formal teaching regarding its utility. Medical Teacher. 2013 Oct; 36(2):155-63. DOI: 10.3109/0142159X.2013.836267.
6. Magar S, Kale AV, Shaikh S, Kale A. Mini-CEX (Clinical Evaluation Exercise) as formative assessment- better appreciated assessment by post graduate students in Paediatrics. NIJP. 2017 Oct-Dec; 6(4):203-9.

7. Malhotra S, Hatala R, Courneya C. Internal medicine residents' perceptions of the mini-clinical evaluation exercise. Med Teach. 2008; 30(4):414-9. doi: 10.1080/01421590801946962.

8. Khalil S, Aggarwal A, Mishra D. Implementation of a Mini-Clinical Evaluation Exercise (Mini-CEX) program to assess the clinical competence of postgraduate trainees in Pediatrics. Indian Pediatr. 2017 Apr 15; 54(4):284-7. Epub 2017 Feb 2.

9. Hill F, Kendall K, Galbraith K, Crossley J. Implementing the undergraduate mini-CEX: A tailored approach at Southampton University. Med Educ. 2009; 43(4):32634.

10. Fernando N, Cleland J, Mckenzie H, Cassar K, Fernando $\mathrm{N}$. Assessment Identifying the factors that determine feedback given to undergraduate medical students following formative mini-CEX assessments. Med Educ. 2008 Jan; 42(1):89-95. Epub 2007 Nov 22.

11. Burch VC, Seggie JL, Gary NE. Formative assessment promotes learning in undergraduate clinical clerkships. S Afr Med J. 2006 May; 96(5):430-3.

12. Al-wardy NM. Assessment methods in undergraduate medical education. Sultan Qaboos Univ Med J. 2010 Aug; 10(2):203-9. Epub 2010 Jul 19.

13. de Lima AA, Henquin R, Thierer J, Paulin J, Lamari N, Belcastro $F$, et al. A qualitative study of the impact on learning of the mini clinical evaluation exercise in postgraduate training. Med Teach. 2005; 27(1):46-52.

14. Gade SA, Chari SN, Chalak A. Use of mini-CEX as a teaching learning method in physiology for undergraduate medical students. Natl $\mathrm{J}$ Physiol Pharm Pharmacol. 2017; 7(5):482-5.

15. Ramula M, Arivazagan N. Mini-clinical examination (mini-CEX) as a tool for formative assessment for surgical interns. International Journal of Surgery Science 2018 Mar; 2(4): 19-22.

16. Singh T, Sharma M. Mini-clinical examination (CEX) as a tool for formative assessment. Natl Med J India. 2010 Mar-Apr; 23(2):100-2.

17. Yousuf N. Mini clinical evaluation exercise: Validity and feasibility evidences in literature. Educ Med $\mathrm{J}$. 2012; 4(1):100-7. 
18. Lin CS, Chiu TF, Yen DHT, Chong CF. Mini-clinical evaluation exercise and feedback on postgraduate trainees in the emergency department: A qualitative content analysis. J Acute Med [Internet]. 2012; 2(1):17.

19. Humphrey-Murto $S$, Côté $M$, Pugh D, Wood TJ. Assessing the validity of a multidisciplinary mini-clinical evaluation exercise. Teaching and Learning in Medicine. 2018; 30(2):152-61. DOI: 10.1080/10401334.2017.1387553.
20. Cook DA, Beckman TJ, Mandrekar JN, Pankratz VS. Internal structure of mini-CEX scores for internal medicine residents: Factor analysis and generalizability. Adv Health Sci Educ Theory Pract. 2010 Dec; 15(5):633-45. doi: 10.1007/s10459-010-92249. Epub 2010 Feb.

21. Behere R. Introduction of mini-CEX in undergraduate dental education in India. Educ Heal Chang Learn Pract. 2014; 27(3):262-8.

22. Chang YC, Chen $\mathrm{CK}$, Chen JC, Liao $\mathrm{CH}$, Lee $\mathrm{CH}$, Chen YC, et al. Implementation of the mini-clinical evaluation exercise in postgraduate Year 1 residency training in emergency medicine: Clinical experience at Chang Gung Memorial Hospital. J Acute Med. 2013; 3(3):110-5.

\begin{tabular}{|c|l|l|l|}
\hline \multicolumn{4}{|c|}{ AUTHORSHIP AND CONTRIBUTION DECLARATION } \\
\hline Sr. \# & \multicolumn{1}{|c|}{ Author(s) Full Name } & \multicolumn{1}{|c|}{ Contribution to the paper } & Author(s) Signature \\
\hline 1 & Mahrukh Ikram Shah & $\begin{array}{l}\text { Main Author Corresponding } \\
\text { Author } \\
\text { 2nd Author }\end{array}$ \\
\hline 2 & Iftikhar Qayum & 3rd Author \\
\hline 3 & Nazish Bilal & 4th Author & \\
\hline 4 & Sajid Ahmed & \\
\hline
\end{tabular}

